\title{
Hemorragia digestiva alta desencadenada por un cuerpo extraño
}

\author{
R. Ramos, P. Duarte, C. Vicente y C. Casteleiro \\ Servicio de Aparato Digestivo. Hospital Universitário de Covilhã. Portugal
}

\section{INTRODUCCIÓN}

La ingesta accidental de cuerpos extraños es un problema comúnmente encontrado en la población pediátrica y en los adultos. La literatura sugiere que el tratamiento endoscópico de extracción de los cuerpos extraños que pasan al estómago no es necesario, una vez que estos no provocan síntomas, dado que en el 80\% son expulsados de forma espontánea (1).

\section{OBSERVACIÓN CLÍNICA}

Un varón de 75 años, sin antecedentes de interés, ingresó en el servicio de urgencias por un cuadro de hematemesis. El cuadro se inició 3 días antes de su ingreso con dolor abdominal tras la ingesta de un hueso de pollo. La exploración física mostraba palidez cutáneo-mucosa, con tendencia a la hipotensión arterial (TA: 90/55 mmHg), con una frecuencia de 128 pulsaciones por minuto. La analítica mostraba anemia (Hb: 6,9 g/dl).

Tras transfusión de concentrados de hematíes se realizó endoscopia digestiva alta de urgencia, apreciando en el fundus de la cavidad gástrica un cuerpo extraño con hemorragia activa (Fig. 1). Se decidió extraer endoscópicamente el cuerpo extraño, desencadenando una hemorragia de gran cantidad (Fig. 2); que se detuvo con la inyección de 1 cc de la mezcla ( $0,5 \mathrm{cc}$ de cianoacrilato e $1,5 \mathrm{cc}$ de lipiodol). En el estudio anatomopatológico del cuerpo extraño se verificó que se trataba de un hueso de pollo (Fig. 3). No hubo ninguna recurrencia hemorrágica y se repitió la endoscopia en la semana 2 y la semana 8, no observándose lesión alguna.

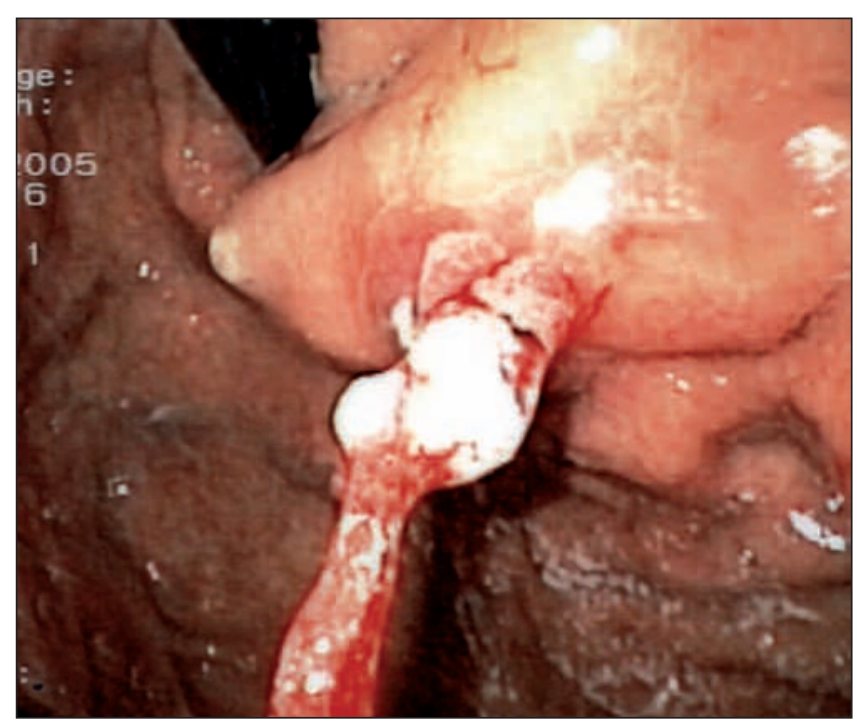

Fig. 1. Cuerpo extraño en el fundus gástrico y hemorragia activa intensa.

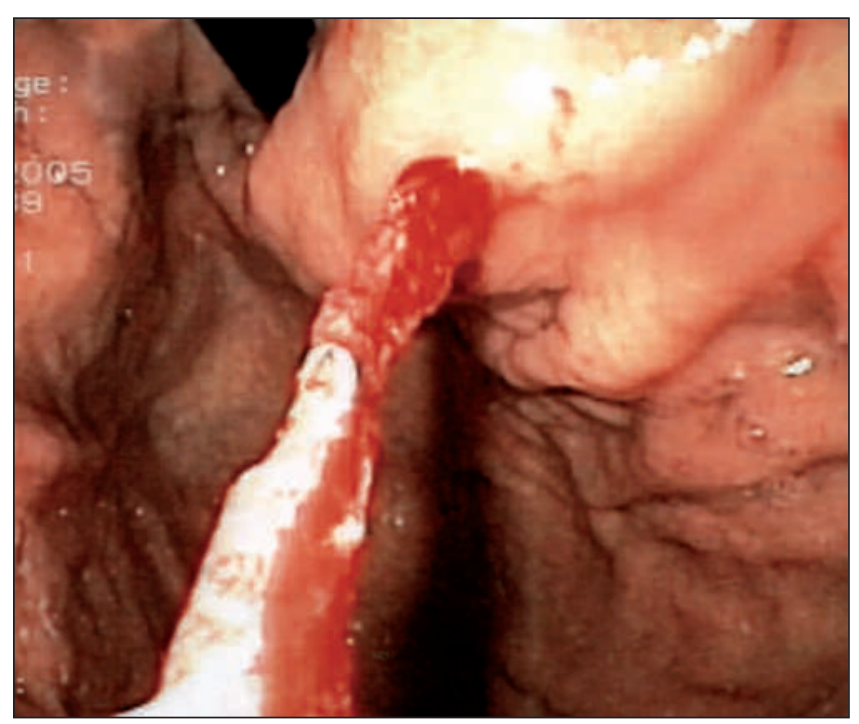

Fig. 2. Extracción endoscópica de cuerpo extraño provocando hemorragia intensa. 


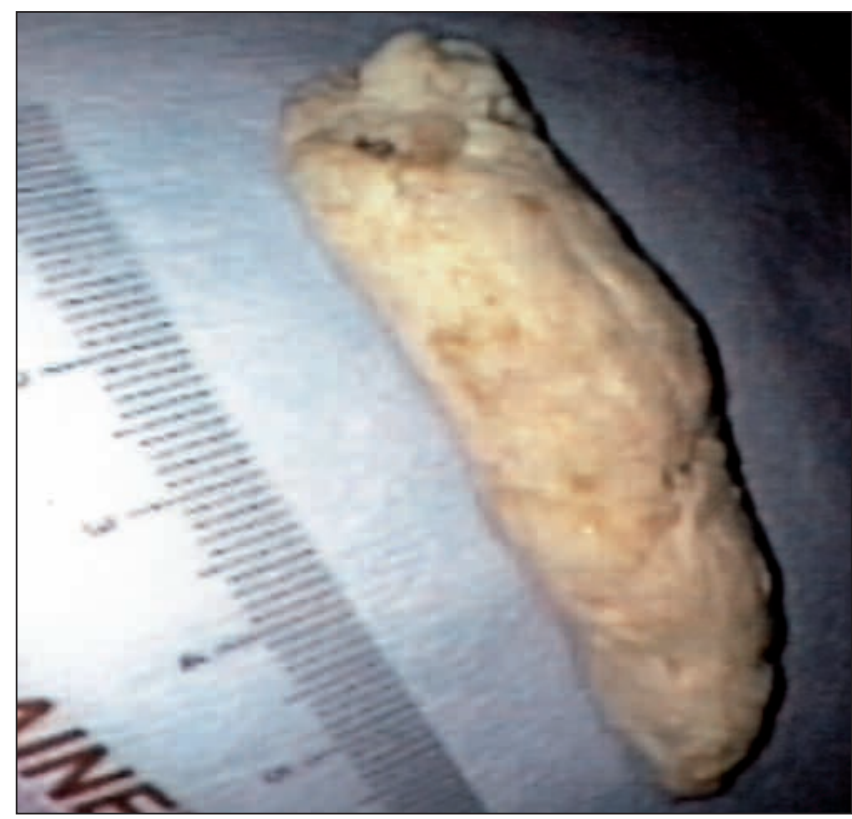

Fig. 3. Hueso de pollo.

\section{DISCUSIÓN}

La ingestión accidental de cuerpos extraños es más frecuente en pacientes con déficit sensitivos asociados a enfermedades vasculares del cerebro, enfermedades psiquiátricas y pacientes con disminución de la sensibilidad en el palato debido al uso de prótesis dentarias (2). El lugar más frecuente del impacto de los cuerpos extraños tras pasar el esófago implica la zona íleo-cecal y el colon sigmoideo, provocando abscesos, fístulas, a menudo perforación (3).

En el caso que presentamos el tratamiento endoscópico de la hemorragia digestiva alta con inyección de cianoacrilato fue una buena técnica y efectiva para detener la hemorragia.

\section{BIBLIOGRAFÍA}

1. Kubota $\mathrm{Y}$, Tokiwa $\mathrm{K}$, Tanaka S, Iwai N. Intestinal obstruction in an infant due to magnet ingestion. Eur J Pediatr 1995; 5: 119-21.

2. Maglinte DD, Taylor SD. Gastrointestinal perforation by chicken bones. Radiology 1979; 130: 597-9.

3. Kill C, Rosemberg J. Gastric intramural abscess successfully drained during gastroscopy. Gastrointestinal Endosc 2001; 53: 231-2. 